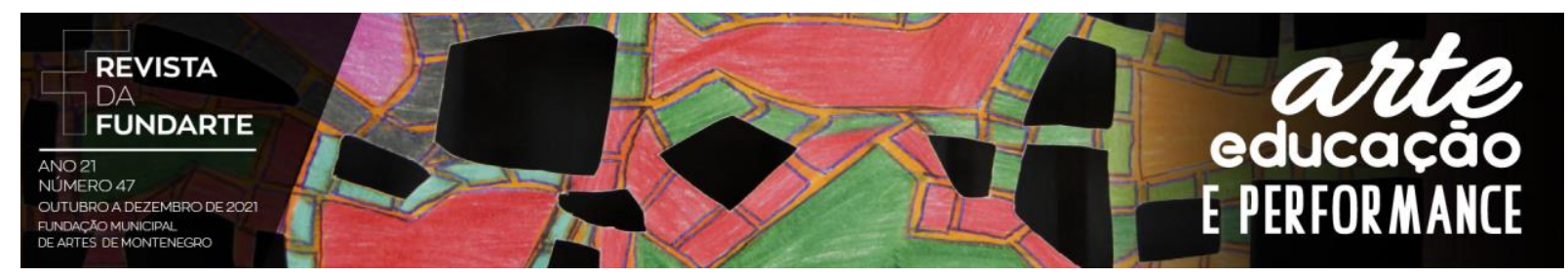

\title{
HIATOS DO HUMANO: PROCESSOS DE CRIAÇÃO EM DANÇA MOTIVADOS PELA PANDEMIA DA COVID-19
}

Diego Ebling do Nascimento Sílvia da Silva Lopes

Resumo: A pesquisa em dança foi motivada pelas reflexões e pelos sentidos que o afastamento social ocasionado pela pandemia da COVID-19 produziu em nossos corpos. A escolha metodológica tem como estratégia a pesquisa guiada-pela-prática e está fundamentada na pesquisa performativa e na abordagem fenomenológica. O processo artístico foi impulsionado pela interrogação "como a experiência da pandemia pode nos transformar?". O texto está dividido em três partes: a primeira aborda o processo de concepção da obra, a segunda expõe o referencial teórico-metodológico e, por fim, a terceira parte descreve o processo de criação e compartilha três cenas do Hiatos do Humano.

Palavras-chave: Dança contemporânea; Distanciamento social; Videodança.

\section{HUMAN HIATUSES: DANCE CREATION PROCESSES MOTIVATED BY THE COVID-19 PANDEMIC}

\begin{abstract}
Dance research motivated by the reflections and the senses that the social withdrawal caused by the pandemic of COVID-19 produced in our bodies. The methodological choice based on practice-guided research and based on performative research and the phenomenological approach. The artistic process was driven by the question "How can the pandemic experience change us?". The text is divided into three parts: the first addresses the process of designing the work, the second exposes the theoretical-methodological framework and, finally the third part describes the creation process and shares three scenes from the Hiatos do Humano.
\end{abstract}

Keywords: Contemporary dance; Social distancing; Video-dance.

\section{Primeiros movimentos: o processo de concepção da obra}

Eu sabia que tinha que achar uma forma de dança do tempo no qual nós vivemos.

Mary Wigman

Este trabalho é um recorte de uma pesquisa em dança realizada em um Trabalho de Conclusão de Curso da Graduação em Dança: Licenciatura na Universidade Estadual do Rio Grande do Sul (UERGS). Apresentamos poeticamente as vivências e experiências por meio da produção artística em dança ao longo do período da quarentena ocasionada pela disseminação do novo Corona-vírus. 


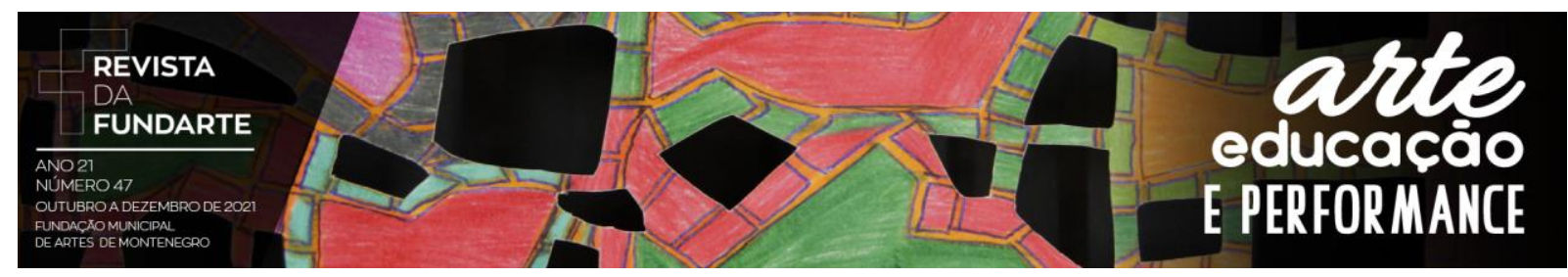

Por meio de experimentos dançantes e jogos de improvisações em dança, criamos diversos vídeos que estão disponíveis na plataforma do YouTube no Canal "Diego Ebling" que compõem o Hiatos do Humano. Eles podem ser acessados por meio dos hiperlinks que se encontram ao longo da escrita deste trabalho.

Nosso objetivo foi realizar um trabalho artístico em dança que subvertesse o afastamento social sem expor quaisquer pessoas aos riscos da propagação do vírus. Como objetivos específicos nos propomos a interrogar as relações entre a arte e a vida durante a quarentena da COVID-19, além de proporcionar outros modos de estar em dança frente à pandemia. Assim, com este artigo, apresentaremos parte do processo de criação Hiatos do Humano, em três videodança.

O neoliberalismo, enraizado em nossa sociedade, tem proporcionado formas de estar no mundo contemporâneo cada dia mais cruéis, exemplo disso é o agravamento das injustiças sociais; a intensificação do desmatamento; o aumento da violência policial; o assassinato desenfreado da população negra nas favelas e das pessoas LGBTQIA+; os posicionamentos desumanos do presidente da República; a banalização das mortes por COVID-19 e as impunidades dos crimes cometidos no meio político. Os fatos mencionados agravaram-se durante a pandemia devido a quarentena, evidenciando a necessidade coletiva de repensarmos urgentemente nossas formas de estar no mundo. Tanto a Dança quanto a Educação, ambas, nossos lugares de produção de sentidos, são potentes frentes de embate à essa lógica perversa neoliberal. Assim sendo,

[...] repensar a educação e a dança no mundo contemporâneo quer no âmbito artístico profissional, quer na escola básica, significa também repensar todo o sistema de valores e ideais concebidos desde o século XVIII e que foram incorporados no pensamento ocidental. (MARQUES, 2011, p. 55).

Em outros momentos da história da humanidade passamos por situações desafiadoras que geraram mudanças significativas nos nossos modos de vida, por problemas políticos, sociais e econômicos que foram vividos pelas pessoas, registrados e/ou levados à cena por diferentes artistas, produzindo novas poéticas de dança. 


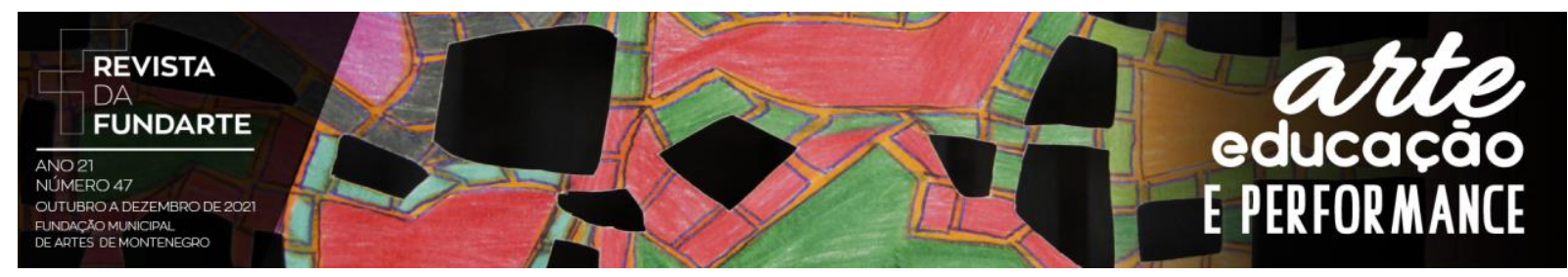

Podemos citar como exemplo a emergência da Dança Moderna, com a Dança Expressionista de Mary Wigman. Ela confiava na "capacidade de expressar a desordem espiritual e o estado de caos e desesperança pós-primeira guerra mundial, traduzindo a realidade de sua época [...]. O desespero e a revolta pelas conseqüências [sic] da guerra e a ascensão nazista marcaram suas interpretações" (GARCIA; HAAS, 2006, p. 91). Ela produziu diversos trabalhos coreográficos e trazia as experiências vividas como fonte de inspiração e estímulos na criação de movimentos, personagens ou cenas. Faz-se importante ressaltar, dentre as suas obras, a Dança de Niobe, "onde ela se vale da sua passagem num búnquer para traçar uma relação entre o mito grego e as mulheres que perderam seus filhos na guerra" (MORAIS, 2019, p. 11), "o horror de ter estado num abrigo antiaéreo a levou a uma dança onde uma mãe embala uma criança" (MORAIS, 2019, p. 29).

Outro exemplo foi o surgimento do Movimento Hip-hop, nos Estados Unidos na década de 1960 em meio à crise econômica, à Guerra do Vietnã, à discriminação da população negra, africana e latina moradora das periferias do país. Gustsack (2003) e Camargo (2013) afirmam que a cultura Hip-hop era uma forma da periferia e de seus representantes expressarem a força das classes excluídas, com a finalidade de reivindicar e reconhecer direitos políticos e sociais da população periférica e, de acordo com as pesquisas de Moreno e Almeida (2009). O Movimento segue sendo uma forma de militância e engajamento político até hoje.

Ainda podemos citar as contribuições do surgimento da performance que vai ter, para Glusberg (2013, p. 90), "tanto um valor de denúncia quanto de um demonstrativo dramático de gestos, adquirindo o estatuto privilegiado de enfrentarse com o óbvio, o simples e o mais natural". Ela é "uma arte de intervenção, modificadora, que visa causar uma transformação no receptor" (COHEN, 2013, p. 46).

Assim como as/os artistas e pesquisadoras/es aqui citados, nosso trabalho foi influenciado pelas questões do nosso tempo, que emergiram pela necessidade do distanciamento social. Tanto a limitação das relações presenciais quanto o avanço da utilização das tecnologias digitais atravessaram nosso processo de 


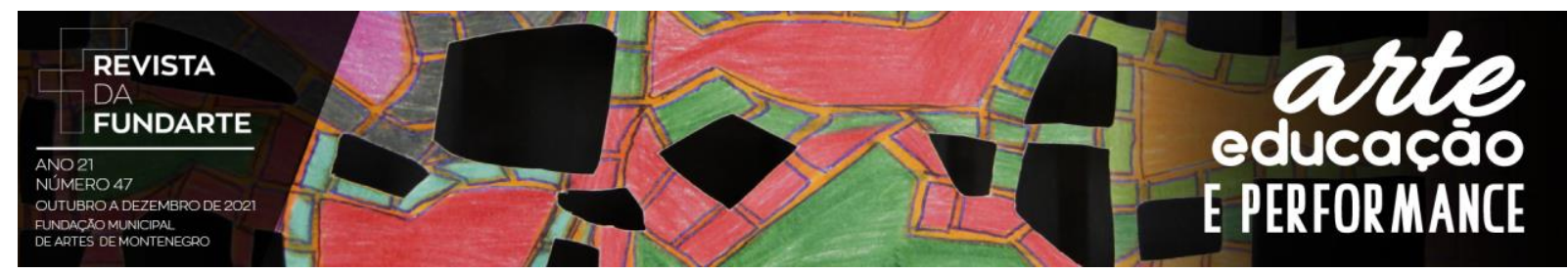

criação. Nesse sentido, os modos de apresentar a obra se delinearam durante o processo sem que houvesse um planejamento antecipado de seu formato.

Percebemos diversos artistas ao longo da história que propuseram outras formas de fazer dança as quais surgiram diante das condições que o momento social, econômico e político de diferentes épocas e lugares incitaram. Poderíamos citar diversas outras manifestações de danças criadas e desenvolvidas ao longo da história como exemplos de relações entre o mundo-vivido e o mundo-imaginado. No entanto, a escolha de recordar esses trabalhos aconteceu de forma intencional, devido as percepções das sutilezas proximais que eles apresentam em relação as emergentes demandas da pandemia da COVID-19. Diante disso, os exemplos apresentados nos auxiliam a perceber que encontrar meios dançantes de subversão do sistema político injusto, desigual e desumano que estamos submetidos é o que move a justificativa deste trabalho.

Entretanto, temos consciência que nenhuma dessas experiências supracitadas podem ser comparadas de forma direta e simplificadora à atual experiência de viver a pandemia. São tempos, espaços, pessoas e histórias diferentes. Nossa intenção, com isso, é apenas poder pensarmos sobre as relações entre a arte e a vida hoje. Desse modo, sabemos que atualmente a pandemia e o distanciamento social instauraram a necessidade de pensarmos em outros processos artísticos emergentes do nosso tempo.

Holanda e Lima (2020) nos lembram que, mesmo diante de toda a crise do Coronavírus, os movimentos político-culturais, promovidos por diversos segmentos artísticos, seguem resistindo e lutando pelos direitos da classe artística exercer criativa e politicamente a profissão. Nós enquanto professores-artistas da dança também fazemos parte desse movimento e diante de toda complexidade dos fenômenos expostos, compartilhamos o entendimento da dança como um lugar de luta, resistência e (re)existência dos nossos corpos ao mundo neoliberalcontemporâneo.

A obra propõe aproximações com o conceito de tempo/duração explanado por Bachelard. $O$ autor problematiza a ideia de tempo contínuo apresentada na tese bergsoniana, considerando que existem lacunas na sua duração. 


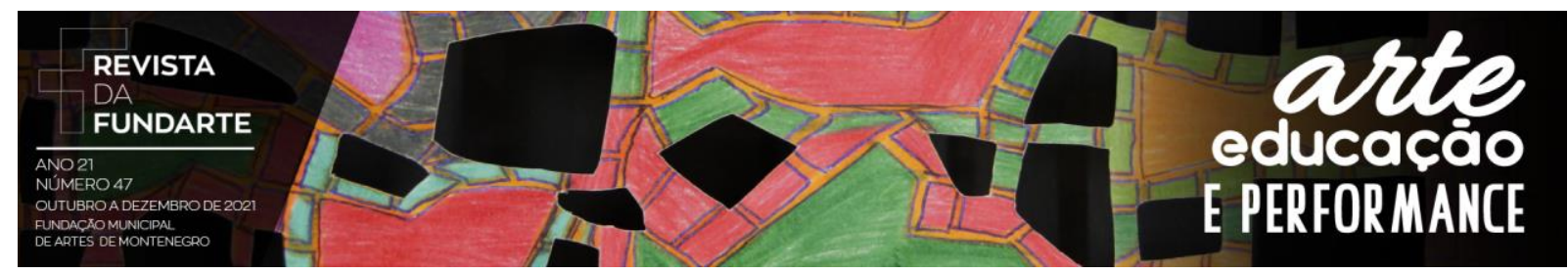

O tempo tem várias dimensões, o tempo tem uma espessura. Só aparece como contínuo graças à superposição de muitos tempos independentes. Reciprocamente, qualquer psicologia temporal unificada é necessariamente lacunar, necessariamente dialética. (BACHELARD, 1994, p. 87).

Levando em consideração que "a fenomenologia sempre comporta uma dualidade de acontecimentos e intervalos" (BACHELARD, 1994, p. 7) pretendemos, com esse trabalho, acessar lembranças e memórias recentes do vivido no ano de 2020, e como nos lembram De Medeiros e Cormineiro (2018, p. 31), quando refletem sobre a teoria de Bachelard, "o instante da lembrança traz em si uma ruptura da sucessão, ou melhor, traz em sua constituição a descontinuidade da memória". Assim, "construída sob a influência do instante e da descontinuidade, a memória não se realizaria, enquanto 'fenômeno temporal íntimo, numa trama objetiva', mas em uma temporalidade psicológica lacunar pautada por tramas subjetivas" (BACHELARD, 1994, p. 36-37 citado por DE MEDEIROS; CORMINEIRO, 2018, p. 31).

A continuidade psíquica coloca, em nossa opinião, um problema, e parecenos impossível não reconhecer a necessidade de basear a vida complexa numa pluralidade de durações que não têm nem o mesmo ritmo, nem a mesma solidez de encadeamento, nem o mesmo poder de continuidade. (BACHELARD, 1994, p. 7).

Então, caso você for direto para o YouTube, aproveite a (des)continuidade apresentada por Bachelard por meio da duração lacunar do tempo e jogue com os vídeos, construa seu próprio caminho e pensamento lacunar, já que "as lacunas tornam-se fundamentais pois quanto mais o pensamento é lacunar, mais ele é claro; quanto mais breves suas ordens, mais poderosas. Tomados no instante, não somos senão uma sequência de ritmos, uma série ordenada de recomeços" (RICHTER, 2006, p. 247).

O tempo das nossas vivências e memórias, tal qual nosso pensamento, também é lacunar, a espessura e as lacunas mencionadas podem ser compreendidas quando percebemos que o tempo do pensamento é verticalizado em relação ao tempo comum das coisas que é horizontal (CARVALHO FILHO, 2012, p. 59) e "[a] continuidade na eficácia das motivações intelectuais não reside no plano 


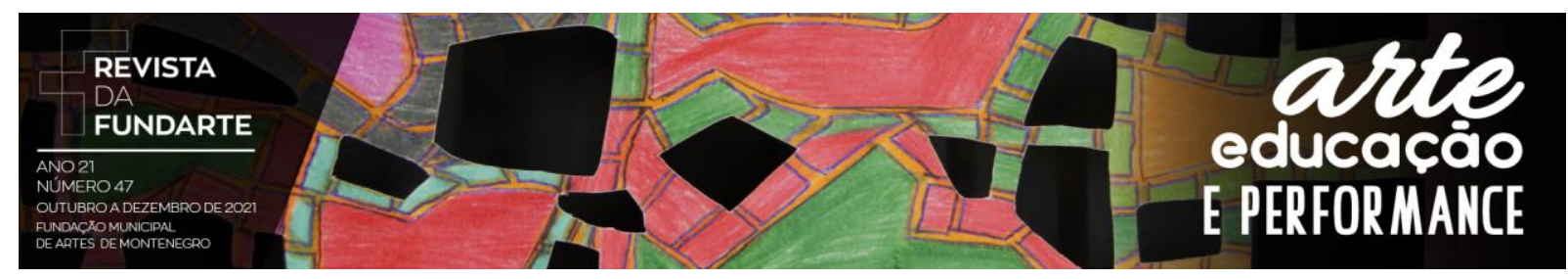

intelectual; nós supomos no plano das paixões, no plano dos instintos, no plano dos interesses" (BACHELARD, 1994, p. 7, grifos do autor).

Desse modo, partindo da premissa que essa pesquisa é um pensamento em dança, acesse a ordem dos vídeos por instinto, veja quais deles te interessam e te apaixonam. Imergimos e compartilhamos reflexões e devaneios poéticos sobre nossa existência neste período complicado, atordoante e desumano que estamos vivendo para deixar emergir poesia e esperança, resiliência e resistência, amor e alteridade.

Ao dançar apresentamos parte do nosso cotidiano pandêmico e que se apresentam como materialidades do mundo-vivido a serem poetizadas no mundoimaginado. Também apresentamos diferentes elementos da natureza que atravessaram o trabalho para emergir sentidos poéticos em nossos corpos.

Trabalharemos com a metáfora do hiato, da fenda, das lacunas e das fissuras. Quando iniciou a pandemia uma grande fenda começou a se abrir em todo o planeta, por vezes achávamos que se abriria tão rapidamente a tal ponto de sermos engolidos por ela. Por outro lado, algumas pessoas nem percebiam que ela estava ali, continuando suas vidas. Esse número de pessoas, que parecem estar cegas da realidade, infelizmente tem aumentado a cada dia. A fenda aberta engana sobre sua espessura.

Escolhemos o a palavra hiato pois na linguística ela se configura quando duas vogais estão juntas, porém em sílabas separadas - vizinhas. $\mathrm{Na}$ anatomia é uma fenda ou abertura no corpo humano. No sentido figurado é uma interrupção entre dois acontecimentos, um intervalo em determinada atividade, uma lacuna.

Com Hiatos do Humano tratamos tanto das fendas, lacunas e fissuras produzidas por quem acredita e aposta na ciência, na arte e na vida, quanto por aqueles que cismam em afirmar que a terra é plana e que o vírus que nos rondeia não existe ou é apenas uma gripezinha. Assim, podemos compreender também a própria atitude dessas pessoas como lacunas da ignorância, fissuras da alma, e, logo, hiatos do humano. 


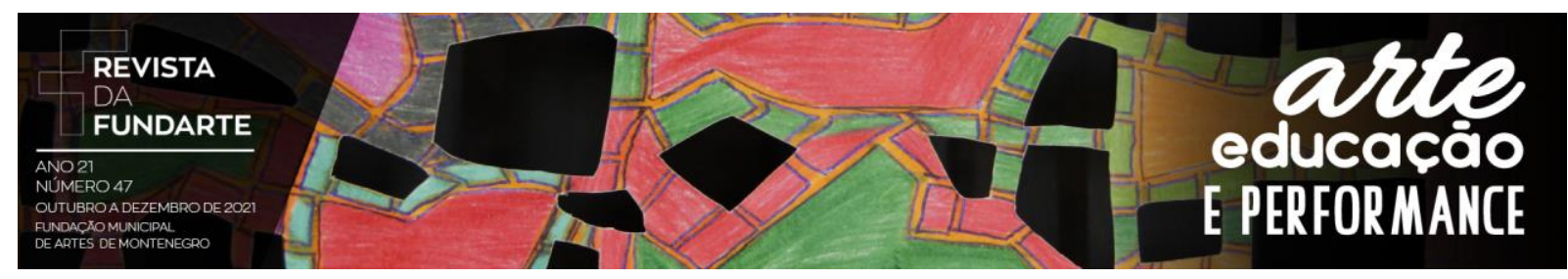

De tal modo, te convido a pensar quais atravessamentos, fendas e/ou suspensões a pandemia da COVID-191 ocasionou na sua vida? (Con)Viver com esse vírus te deslocou para algum lugar? Para onde? O que mudou? Quais são os hiatos que emergiram na sua vida durante pandemia?

\section{Um novo caminho, um novo paradigma: a pesquisa performativa e fenomenológica como estratégia para a pesquisa em dança}

Nosso percurso acadêmico se deu entre as áreas da Educação Física, da Educação e da Arte, realizando pesquisas sobre Dança. Na área da Educação Física os estudos quantitativos são predominantes, no entanto, nossas escolhas metodológicas, desde o princípio, sempre estiveram no campo das Ciência Humanas, especialmente inseridas na abordagem qualitativa.

Ao nos depararmos com esta pesquisa, percebemos que tanto o paradigma da pesquisa quantitativa quanto o da qualitativa não dariam conta de abarcar as necessidades da presente investigação. Percebemo-nos saindo conscientemente do campo da pesquisa sobre dança e entrando no campo da pesquisa em dança.

Tal fato produz um deslocamento nos nossos modos de fazer pesquisa, coerente com a dinamicidade proposta pela criação artística trazida nos estudos de Salles (2016). Para a autora, a criação artística se "põe [...] em contato com um ambiente que se caracteriza pela flexibilidade, não fixidez, mobilidade e plasticidade" (SALLES, 2016, p. 12, grifos da autora). Assim, ao adentrar o universo

\footnotetext{
1 Segundo o site do Ministério da Saúde (2020, online) "a COVID-19 é uma doença causada pelo coronavírus, denominado SARS-CoV-2, que apresenta um espectro clínico variando de infecções assintomáticas a quadros graves". O novo coronavírus (SARS-CoV-2) foi identificado em dezembro de 2019 em Wuhan na China. De acordo com a Organização Mundial de Saúde, cerca de 80\% dos pacientes com COVID-19 podem ser assintomáticos ou apresentarem poucos sintomas, e aproximadamente $20 \%$ dos casos detectados requer atendimento hospitalar por apresentarem dificuldade respiratória, dos quais aproximadamente $5 \%$ podem necessitar de suporte ventilatório. A transmissão da COVID-19 acontece de uma pessoa doente para outra ou por contato próximo por meio de toque do aperto de mão contaminadas; gotículas de saliva; espirro; tosse; catarro; e objetos ou superfícies contaminadas, como celulares, mesas, talheres, maçanetas, brinquedos, teclados de computador etc. (Ministério da Saúde, 2020). Em poucos meses a doença se espalhou por todo o planeta, produzindo pânico na população do mundo inteiro. A pandemia da COVID-19 superlotou hospitais ocasionando pane nos sistemas de saúde de países subdesenvolvidos e desenvolvidos, levando à morte milhares de pessoas.
} 


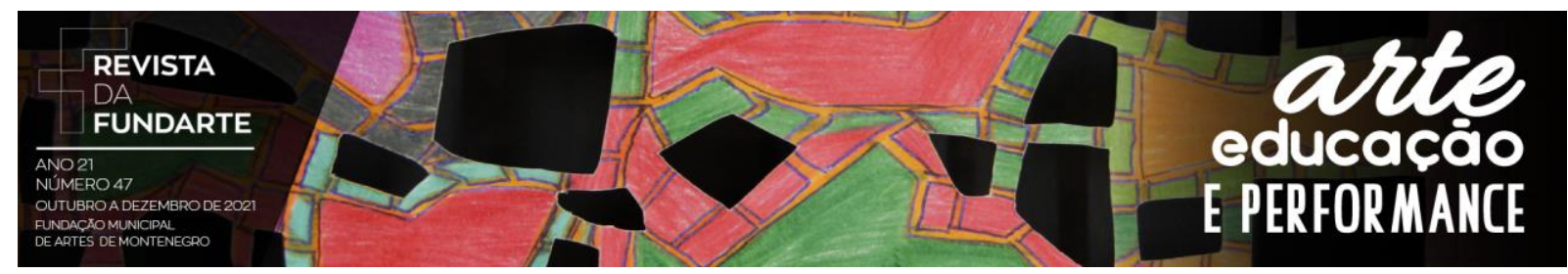

da pesquisa acadêmica em arte, em dança, deparamo-nos com a necessidade de pensar em outros modos de fazer, em outras metodologias.

Nossos estudos têm nos dado a oportunidade de exercitar a experiência fenomenológica, o que vem nos constituindo como pesquisadores que reconhecem, compreendem e valorizam o vivido e a experiência, percebendo-os como fundantes do nosso ser e como potência na produção de sentidos. De acordo com Bicudo (1994, p. 21) a experiência na fenomenologia

[...] é compreendida como experiência vivida. É diferente da experiência compreendida enquanto empírica ou informativa. Para essa concepção, não é o pragma que importa, enquanto experiência das coisas de que o sujeito se ocupa, mas importa a práxis, enquanto agir e fazer, de modo criativo e crítico. O pensar fenomenológico não prescinde da práxis, isto é, da experiência vivida no mundo-vida. A essência de que trata a fenomenologia não é idealidade abstrata dada a priori, separado da práxis, mas ela se mostra nesse próprio fazer reflexivo.

Assim, é possível perceber aproximações com a pesquisa performativa, compreendendo o processo de criação e a relação obra-espectador como experiências de produção de sentido(s), portanto, fenomenológicas.

Já a pesquisa performativa surge na "insistência de que os resultados da investigação e as reivindicações de conhecimento devem ser feitos por meio da linguagem simbólica e [na] forma de sua prática" (HASEMAN, 2015, p. 44), visto que os pesquisadores performativos "têm pouco interesse em tentar traduzir as conclusões e entendimentos da prática nos números (quantitativa) e palavras (qualitativa) preferidos pelos paradigmas tradicionais de investigação" (HASEMAN, 2015, p. 44).

Assim, podemos dizer que a pesquisa performativa surge da capacidade limitada que as palavras apresentam para "captar as nuances e sutilezas do comportamento humano. Nesse sentido, alguns pesquisadores têm utilizado outras formas simbólicas para representar suas reivindicações de conhecimento" (HASEMAN, 2015, p. 45).

Essa insistência em relatar a pesquisa através dos resultados e formatos materiais da prática desafia as formas tradicionais de representação da reivindicação de conhecimento. Significa ainda que as pessoas que 


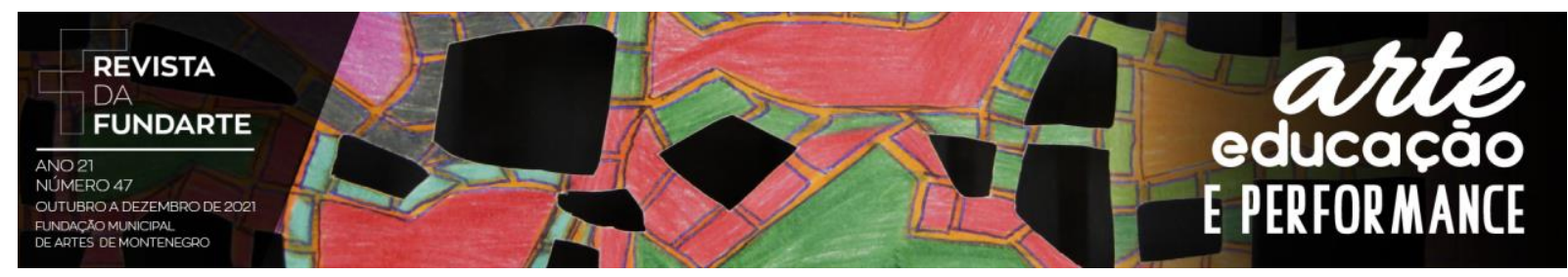

desejam avaliar os resultados da pesquisa também precisam experimentálos de forma direta (copresença) ou indireta (assíncrono, gravado) .(HASEMAN, 2015, p. 45).

Para Haseman (2015, p. 48) a pesquisa performativa é "um movimento que sustenta que a prática é a principal atividade de pesquisa [...] e vê os resultados materiais da prática como representações de suma importância dos resultados de pesquisas em seu próprio direito". O autor afirma que "pesquisadores performativos são construídos como aqueles pesquisadores que realizam pesquisas guiadas-pelaprática” (HASEMAN, 2015, p. 44), ou seja, "a 'prática' em 'pesquisa conduzida-pelaprática' é essencial - não é um extra opcional; é a precondição necessária de envolvimento na pesquisa performativa" (HASEMAN, 2015, p. 48).

Fernandes $(2014$, p. 2$)$ ao propor uma escrita performativa menciona que ela

[...] pode ser aquela organizada pela prática, a partir da prática, em modos imprevisíveis [...]. Assim, a arte deixa de ser apenas um produto ou mesmo um processo a ser descrito, analisado e inserido em outros moldes (por mais abertos e dinâmicos que sejam), e passa a ser em si mesma o modo de (des)organizar discursos e métodos [...]. Ou seja, a prática artística passa a ser a chave-mestra que acessa, conecta e/ou confronta os demais conteúdos, trazendo uma contribuição única para o contexto acadêmico, que muitas vezes torna-se estagnado com seu excesso de regras e normatizações.

Como percebemos, de acordo com Haseman (2015) e Fernandes (2014), a pesquisa performativa tem como estratégia necessária e fundamental a pesquisa guiada-pela-prática. Haseman define essa estratégia como sendo

Em primeiro lugar, a pesquisa que é iniciada na prática, onde dúvidas, problemas, desafios são identificados e formatados pelas necessidades da prática e dos praticantes; e, em segundo lugar, que a estratégia de pesquisa é empreendida através da prática, utilizando predominantemente metodologias e métodos específicos que nos são familiares, como praticantes. (GRAY, 1996, p. 3, citado por HASEMAN, 2015, p. 49).

Podemos dizer, então, que "a pesquisa guiada-pela-prática é intrinsecamente empírica e vem à tona quando o pesquisador cria novas formas artísticas para performance e exibição" (HASEMAN, 2015, p. 44). Assim, essa proposta contempla as necessidades do presente estudo. Nesse sentido, ao falar 


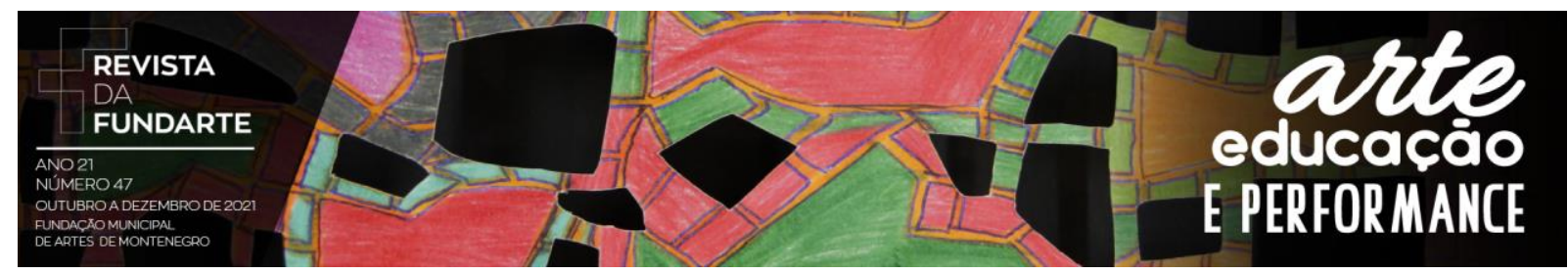

sobre os pesquisadores guiados-pela-prática, Haseman (2015, p. 44) ressalta que muitos

[...] não iniciam o projeto de pesquisa com a consciência de "um problema". $\mathrm{Na}$ verdade, eles podem ser levados por aquilo que é melhor descrito como "um entusiasmo da prática": algo que é emocionante, algo que pode ser desregrado, ou, de fato, algo que somente pode tornar-se possível conforme novas tecnologias ou redes permitam (mas das quais eles não podem estar certos). Pesquisadores guiados-pela-prática constroem pontos de partida empíricos a partir dos quais a prática segue. Eles tendem a "mergulhar", começar a praticar para ver o que emerge. Eles reconhecem que o que emerge é individualista e idiossincrático. Isso não quer dizer que esses pesquisadores trabalham sem maiores agendas ou aspirações emancipatórias, mas eles evitam as limitações das correções de pequenos problemas e das exigências metodológicas rígidas no primeiro momento de um projeto.

Tendo em vista esse argumento apresentado percebemos que essa pesquisa em dança começou sem ter "um problema" específico, mas considerando o que o autor chama de "um entusiasmo da prática".

Cabe salientar que este estudo apresenta contaminações tanto da pesquisa performativa, guiada-pela-prática, quanto da abordagem fenomenológica, reflexo do nosso momento de vida, da nossa constituição enquanto pesquisadores e do próprio processo traçado nesta pesquisa. Realizamos aqui a descrição do vivido, um caminho de afastar-se e aproximar-se da experiência de produzir dança para compor a obra Hiatos do Humano.

A partir disso, o trabalho fez emergir as seguintes interrogações: ser uma pesquisa performativa anula a possibilidade de ser uma pesquisa fenomenológica? Ela poderia ser as duas ao mesmo tempo? Codependentes? Seria possível pensar em uma pesquisa fenomenológica-performativa ou performativa-fenomenológica?

\section{Devaneios, fronteiras e rituais dançantes}

Apresentamos, aqui, como se organizou e se constituiu parte do processo de criação do Hiatos do Humano, mais especificamente as cenas "Água", "Solidão" e "Esperançar". Como já informado anteriormente as videodanças podem ser acessadas por meio dos hiperlinks que se encontram disponíveis a seguir, no título de cada obra. 


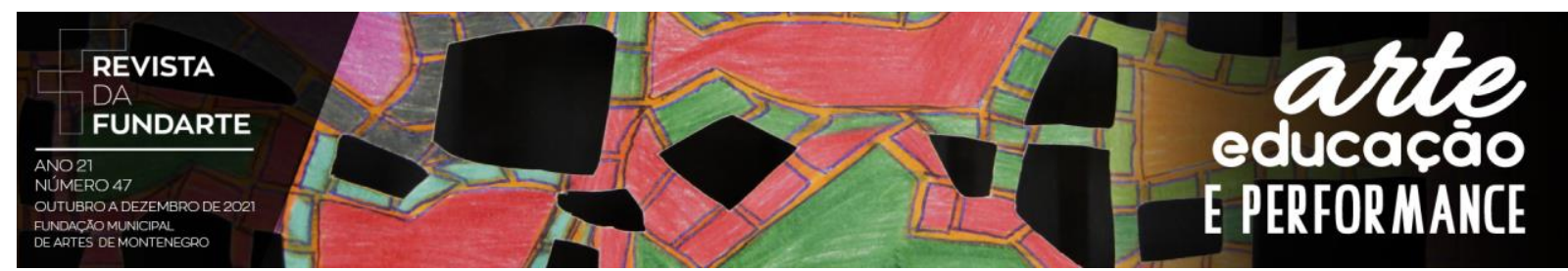

Esta pesquisa em dança iniciou-se em agosto de 2020, com a participação de mais duas artistas. Deste processo resultaram cenas em que elas foram as intérpretes-criadoras e outras em que eu ${ }^{2}$ fui o interprete-criador. Ambas foram realizadas de forma conjunta com minha orientadora. Neste artigo iremos compartilhar os videodanças que foram interpretados por mim.

No início da pesquisa ainda me encontrava em Montenegro, estudando em ensino remoto e enfrentando a quarentena rigorosamente em casa. Ao passar dos meses algumas mudanças na minha vida fizeram com que eu não pudesse mais ficar em um isolamento social e passasse a colocar em prática o distanciamento social. Ainda que eu tome todos os cuidados indicados pela Organização Mundial da Saúde não me encontro mais tão recluso e, portanto, não tão mais protegido como estava no Rio Grande do Sul.

O maior marco dessa transição em minha vida foi meu retorno para o estado do Tocantins, quando uma mudança de rotina me deixou mais exposto à contaminação. É possível perceber que essa situação reverberou no trabalho artístico, os primeiros experimentos produzidos para esse trabalho foram realizados inteiramente dentro de casa. Após meu retorno para Palmas/TO algumas cenas passaram a ser realizadas na rua, respeitando o afastamento social e contando com toda a segurança necessária. Nesse sentido, para o processo de criação das videodanças partimos da questão "como a experiência da pandemia pode nos transformar?".

A grande fenda que foi aberta abruptamente em março de 2020 quando, de um dia para o outro, isolamo-nos em nossas casas, produzindo sentimentos de saudade, incerteza, angústia e ansiedade, com o meu retorno para Palmas/TO, parece que o dilatamento dessa lacuna começou a diminuir para mim. Esse percurso e encontro entre fendas e lacunas, mais e/ou menos espeças, são apresentadas de forma poética ao longo desta pesquisa em dança.

\footnotetext{
${ }^{2}$ Esta pesquisa foi realizada de forma conjunta, porém focada nas experiências do intérprete-criador que foram levadas para a cena. Assim, em determinados trechos do texto faremos a escrita na primeira pessoa do singular.
} 


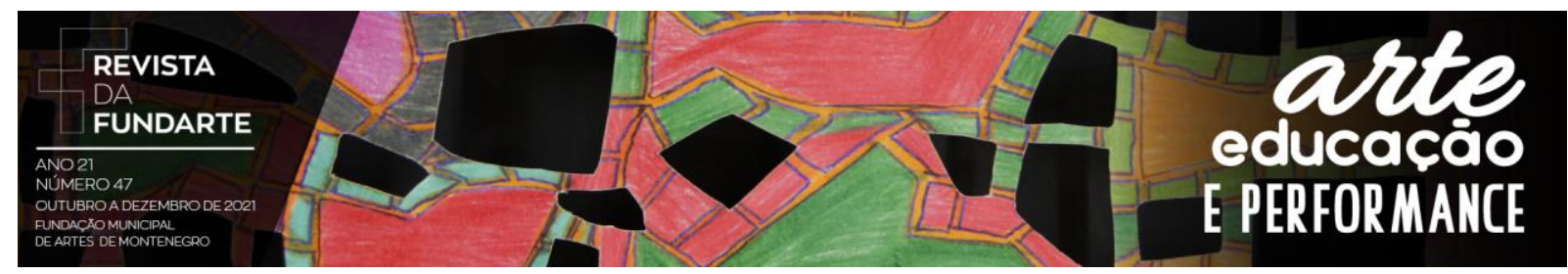

Áqua

A cena é realizada no chuveiro, onde a água escorre pelo meu corpo, mas minha cabeça e cabelos não entram em contato com ela. Essa cena parte de um jogo que estabeleci durante os momentos em que estava me banhando com a água do chuveiro da minha casa. Entendo aqui o banho como um processo ritualístico para a criação do Hiatos do Humano, pois nesses momentos surgiam muitos pensamentos e devaneios sobre o processo de criação do trabalho. $O$ banho passou a ser reconhecido como um ritual-jogo que se fez presente durante o meu período de isolamento social. Em vista disso, nos aproximamos do conceito de ritual trazido por Peirano (2003) que o compreende como um meio de agir maleável, criativo e especial. Além disso, a autora indica que a convencionalidade é outra característica presente nos rituais e que eles fazem parte do nosso dia-a-dia.

O jogo que eu propunha durante esses momentos tinha início no banheiro da minha casa em Montenegro/RS, quando me despia e colocava as músicas que eu pretendia utilizar no Hiatos do Humano. Então ligava o chuveiro elétrico e o barulho da água, a mudança de temperatura, o cheiro do sabonete, começavam a produzir reações no meu corpo, outros pensamentos e devaneios emergiam nesse ritual.

Quando percebia já me encontrava a improvisar, sentindo a água quente que escorria pelo meu corpo. Essa sensação trazia um relaxamento e parecia que as ideias vinham à tona potencializando a criação, de tal modo que o jogo que 0 meu corpo estabelecia com água e que água estabelecia com o meu corpo foi inevitável, as músicas que tocavam, soavam como convite à dançar com a água.

Nesse sentido, percebi que minhas improvisações se aproximavam do conceito de improvisação estruturada de Rolf Gelewski. O autor descreve que "a improvisação estruturada é um processo que visa construir, a partir de poucos elementos iniciais, uma consciência real que possa ser, para o indivíduo, apoio e fonte continuamente promotora de um trabalho de autodescoberta e auto-formação" (GELEWSKI, 1973 citado por PASSOS, 2015). Ainda de acordo com as ideias desse autor, defini, antes de fazer a gravação, um ponto inicial e um final para o improviso 


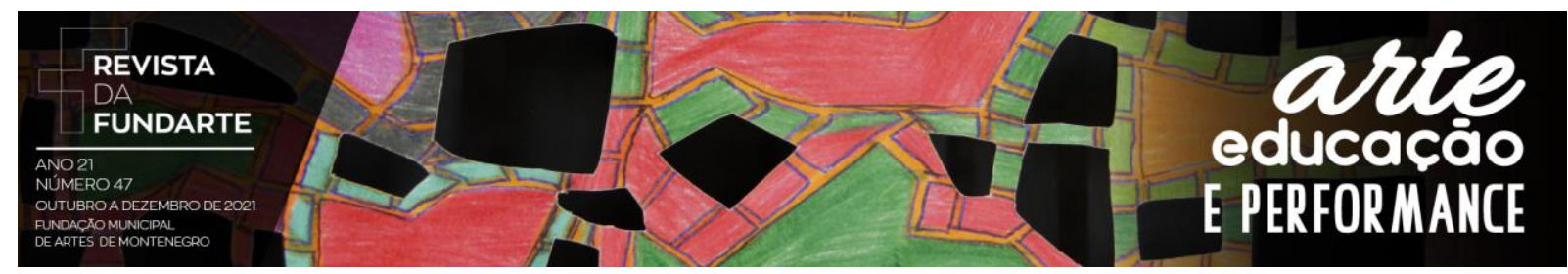

(PASSOS, 2015). Elaborei uma estrutura básica de movimentos a partir do jogo que era estabelecido entre a água e eu.

Tanto essa cena quanto a próxima que relatarei foram gravadas no meu último dia de morada na cidade de Montenegro/RS, em novembro de 2020, quando todas as caixas da mudança estavam no carro. Não conseguia conceber a gravação dessas cenas em outro espaço, sentia que deveria ser ali. Naquela residência, que se tornou um lar, espaço tão especial que acolheu tanto a minha mãe quanto a mim durante todos os dias que passamos juntos na quarentena.

Logo após começarmos o isolamento, minha mãe, que morava em Curitiba/PR, teve um problema de saúde e decidimos que seria melhor morarmos juntos novamente, assim ela se mudou para Montenegro/RS. A pandemia proporcionou a experiência de compartilhar novamente o lar com a minha mãe. Tivemos que nos readaptar a convivência, uma vez que tanto o filho voltar a morar com a mãe quanto a mãe voltar a morar com o filho produz tensionamentos. Estávamos sem morar juntos há quatro anos, embora nos falássemos semanalmente, tanto eu quanto ela mudamos muito e a convivência diária não acontecia desde 2016, quando me mudei para Palmas/TO pela primeira vez.

Essa readaptação nos possibilitou momentos muito especiais que permitiram o reconhecimento de nossas mudanças, fazendo com que nos conhecêssemos novamente, nos reconhecêssemos. Durante os seis meses que moramos juntos, conversávamos quase que diariamente sentados na mesa da sala sobre todas as nossas inquietações, os absurdos que aconteciam no país, o avanço da pandemia, as desigualdades sociais, nossos amores e desamores. Foi ela quem me ajudou a gravar as cenas para o trabalho e com a maior paciência ouvia atenta minhas indicações e ideias para as gravações.

\section{Solidão}

A cena que aconteceu na casa vazia não poderia ser gravada em outro momento, para isso eu fiquei estruturando ela por semanas. Diferentemente da minha cena no chuveiro, a relação do meu corpo com o espaço, na cena da casa vazia, não pôde ser estudada previamente. Os elementos composicionais que eu 


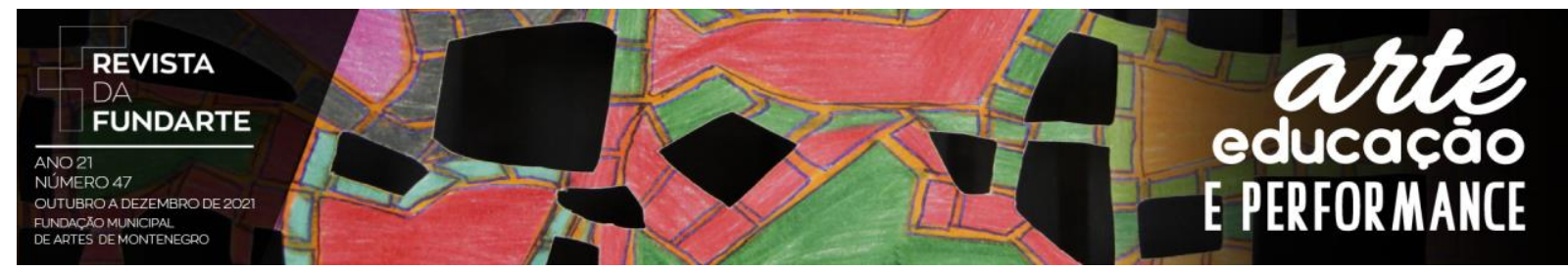

tinha eram a música, que já havia sido escolhida, e a composição espacial que as peças do apartamento produziam. Na estruturação da cena pensei em me relacionar diretamente com as paredes do apartamento.

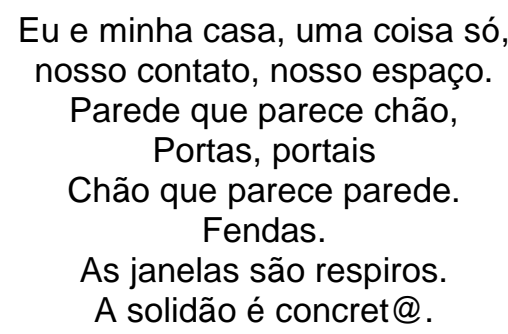

Para a gravação sabia que queria um plano sequência e fui relatando como havia imaginado a direção das imagens para a minha mãe que utilizou o celular para capturá-las. Ela praticamente teve que dançar comigo para me acompanhar durante a peregrinação pelos aposentos do nosso antigo lar. Foi necessário gravar algumas vezes para chegarmos no resultado final.

Nessa perspectiva, inspiro-me em Santos (2018, p. 168) que apresenta o pensamento coreográfico do artista contemporâneo Julyen Hamilton ao situar o campo da abordagem da composição instantânea e desenvolver diversos estudos e performances. Ele propõe utilizar "práticas corporais [que] encontram-se desde o início relacionadas com elementos composicionais por meio do trabalho com a improvisação. Trata-se de um saber incorporado que se estrutura em torno da composição instantânea vista como coreografia" (grifos nossos).

Percebi que durante a prática, improvisando na minha antiga casa vazia, me encontrava em um entre-lugar, pois além de estar fazendo a performance também realizava um ritual. Um ritual de (mu)dança que iluminava e ressaltava a gratidão por aquele espaço que nos deixou mais protegidos, seguros e amados durante 0 período que ali vivemos. Um ritual de até logo para o Rio Grande do Sul, tal como as despedidas comuns realizadas nas relações sociais (PEIRANO, 2003).

Após a gravação foi necessário melhorar a qualidade do som para o vídeo e percebi que faltava algo em relação à música "Mortal Loucura" de Caetano Veloso. Fui procurar outras e encontrei uma versão interpretada por Maria Bethânia. Fiquei apaixonado. Então fiz uma montagem introduzindo essa versão. 


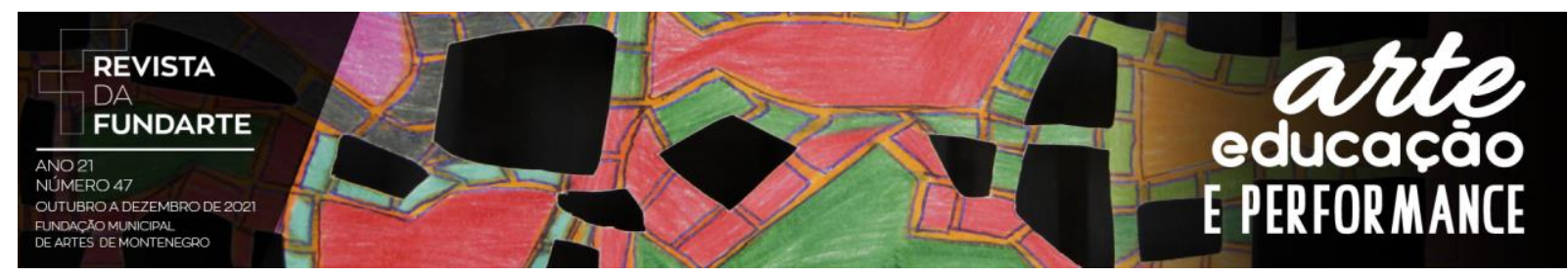

\section{Esperancar}

Essa cena teve como ponto de partida o conceito "esperançar" trazido por Paulo Freire, nesse caminho refletimos sobre a esperança, não a do verbo esperar, mas a do verbo esperançar, trazido pelo autor. Por isso o título da videodança, Esperançar nos motiva a ação que esse próprio verbo produz e também se configura como uma homenagem à uma famosa reflexão de Paulo Freire sobre esperar e esperançar, trazida também por Sérgio Cortella. Nessa videodança propus realizar uma conversa com o público por meio de uma dramaturgia que nos convida a esperançar.

É preciso ter esperança, mas ter esperança do verbo esperançar; porque tem gente que tem esperança do verbo esperar. E esperança do verbo esperar não é esperança, é espera. Esperançar é se levantar, esperançar é ir atrás, esperançar é construir, esperançar é não desistir! Esperançar é levar adiante, esperançar é juntar-se com outros para fazer de outro modo... (FREIRE, 2014, p.10-11).

Para o processo de criação desta videodança também nos inspiramos na composição instantânea e organizamos as narrativas textuais no momento da edição das cenas. O preto da roupa e as chamas das velas remetem ao luto que estamos vivendo diante de tantas vidas interrompidas, ao mesmo tempo em que a luz produzida pelo fogo pode representar a transformação, a reconfiguração dos nossos modos de estar no mundo. Além disso, fazemos uma crítica ao atual governo e lembramos que esperançar é preciso, pois:

A esperança faz parte da natureza humana. Seria uma contradição se, inacabado e consciente do inacabamento, primeiro, o ser humano não se escrevesse ou não se achasse predisposto a participar de um movimento constante de busca e, segundo, se buscasse sem esperança. A desesperança é negação da esperança. A esperança é uma espécie de ímpeto natural possível e necessário, a desesperança é o aborto deste ímpeto. A esperança é um condimento indispensável à experiência histórica. Sem ela, não haveria história, mas puro determinismo. (FREIRE, 2015, p. 70-71).

Quando tudo isso passar poderemos estar juntos e juntas no teatro novamente, nos abraçarmos e sentirmos o calor dos corpos como outrora sempre 


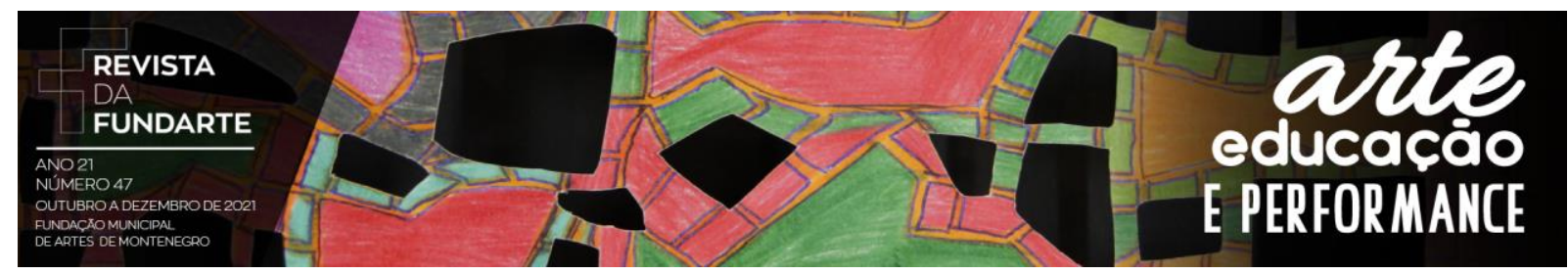

fizemos. Enquanto toda a população brasileira não tiver acesso às vacinas, continuemos a esperançar. Esperancemos juntos um mundo melhor.

\section{Considerações Finais}

Neste artigo discorremos sobre o processo de criação de três videodanças e apresentamos outros e outras artistas da história da dança que já passaram por momentos de modificações abruptas em seus trabalhos artísticos decorrentes dos desafios e das transformações nos modos de viver em seus tempos. Acreditamos que estamos passando por um momento semelhante, com especificidades da nossa época, contando com os recursos tecnológicos e, quem sabe, instaurando um hiato na história da dança, na qual as produções artísticas se configuram pela relação corpo, tecnologia e poética. Isso se torna realidade, pois reconhecemos na dança, tal como os artistas que vieram antes de nós, uma possibilidade de transformação do mundo-vivido, uma possibilidade de resistência e, ao mesmo tempo, de conforto.

Ao longo do processo houve desdobramentos da pergunta principal, nosso objetivo não foi respondê-las, mas ter os questionamentos e interrogações como impulsos para a nossa criação em dança e para fomentar provocações poéticas nos leitores e espectadores. Nessa perspectiva, o texto não visa traduzir as intenções do artista, mas provocar os receptores a perceber quais sensações, interrogações e provocações o trabalho promove.

Durante o processo de criação pensávamos em modos de levar o trabalho artístico ao público e realizamos diferentes experimentações, com isso nos interrogávamos sobre que arte seria essa. Então, optamos pela produção de videodanças e embora os vídeos acompanhem o texto e apresentem uma conexão entre eles, não há uma sequência estrutural preestabelecida que defina sua ordem, isto é, podem ser assistidos a qualquer momento, sem depender do anterior ou do próximo.

Percebemos que o momento de distanciamento social favoreceu a produção de trabalhos artísticos que utilizam os recursos da cibercultura, aproximando cada dia mais o espaço privado e íntimo de nossos lares às relações virtuais. No caso das 


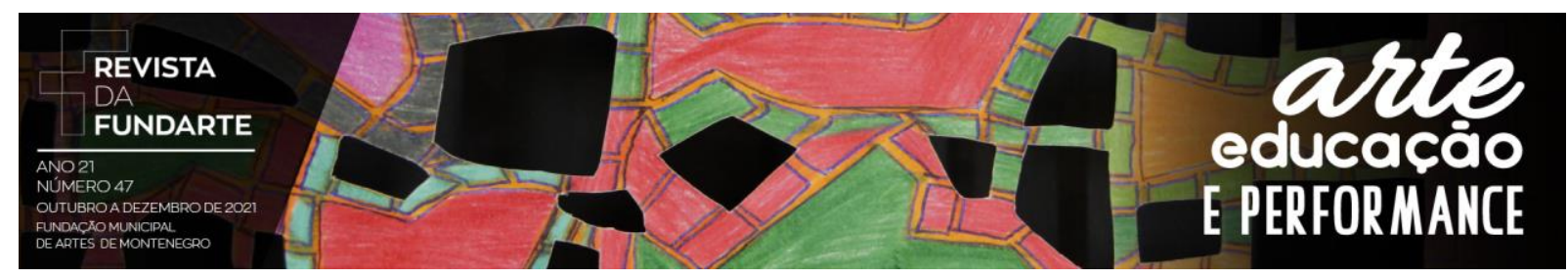

artes cênicas as pesquisas artísticas nesses dois espaços - o privado e o virtual foram potencializadas, valorizadas e necessárias. Assim, a videodança apresenta-se como um entrelaçamento de linguagens, longe de fechar definições, demonstrando a possibilidade de ampliar os modos de produções artísticas situadas nas tênues e cambiantes fronteiras das artes (CERBINO; MENDENÇA, 2011).

Houve hiatos temporais os quais pareciam que a existência do novo Coronavírus não mais circulava entre nós, entre eles: as campanhas políticas no Brasil, atitudes do governo federal, algumas festas que foram realizadas em casas de pessoas famosas por todo o mundo, além da abertura de bares e pubs, aglomerações em praias e eventos particulares. No entanto, reconhecemos que a fenda produzida pela disseminação do novo Coronavírus se encontra ainda bastante dilatada e, mesmo com o início da vacinação, talvez ela possa estar se alastrando ainda mais, visto o crescente número de mortos por COVID-19 já nos primeiros meses de 2021, alcançando, no Brasil, a interrupção precoce de mais de 450 mil histórias.

Hoje, para nós, seria impensável passar todos esses dias confinados sem estar fazendo arte, ela foi nosso refúgio, nossa forma de colocar em dança angústias, pensamentos, devaneios e rituais. Transformar - tal como o fogo faz - o turbilhão de sentimentos que passa pelo nosso corpo em potências criativas dançantes foi o grande desafio e, ao mesmo tempo, a grande realização deste momento tão difícil o qual nos encontramos.

Diante desse desafio o que nos restou foi pensar justamente sobre esse momento que estamos vivendo, jogar com ele, dançar com ele. Por isso é necessário compreender que o corpo que está na dimensão real é o mesmo que está na dimensão ficcional, portanto:

Quanto mais levarmos em conta essa dimensão existencial revelada por meio do nosso corpo, quanto mais considerarmos as dúvidas e os questionamentos que nascem na relação com o mundo exterior, mais proveitoso poderá vir a ser o trabalho realizado e tanto mais rico o resultado obtido. (VIANNA, 2005, p. 111). 


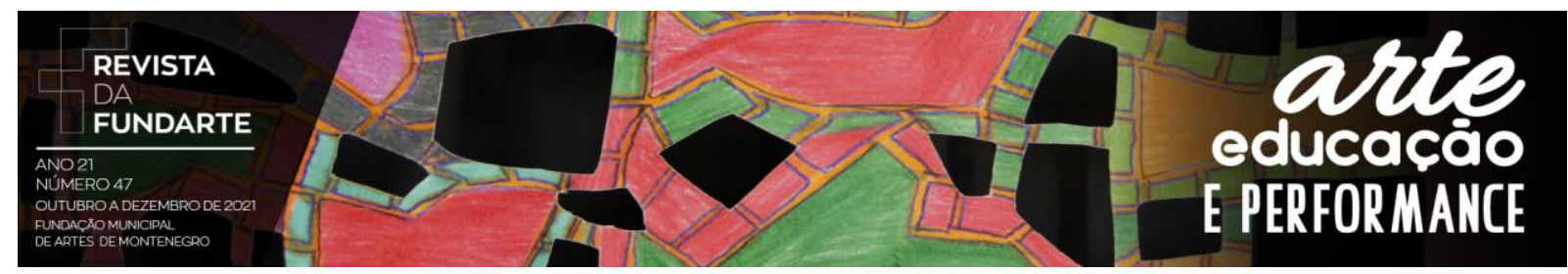

Assim, utilizamo-nos de improvisações para impulsionar e fazer aparecer nossas inquietações no trabalho artístico. Nossas ideias, vivências e experiências diante do mundo pandêmico, o qual estamos vivendo, arquitetaram o Hiatos do Humano.

É importante ressaltar que esse trabalho não teve como objetivo discutir a teoria da videodança, mas utilizamos essa linguagem para colocar nosso trabalho no mundo. Nessa perspectiva, se faz necessário considerar que Cerbino e Mendonça (2011, p. 3243) compreendem que a videodança vai além da "simples soma de vídeo e dança, esse se apresenta como um espaço de experimentação, que surge do encontro entre corpo, imagem e movimento". Caldas (2009) citado por Santos (2015, p. 66) considera que a videodança é "uma das manifestações da dança contemporânea que estabelece uma relação entre dança e tecnologia e que tem suas criações marcadas pela tecnologia da imagem. Estas condições são vistas pelo autor como causadoras de novos estatutos no cenário da dança". Segundo ele "as novas tecnologias tencionam a dança à sua reinvenção; visto a possibilidade de extrapolar os limites da fisicalidade e anatomia corporal, assim como seus limites espaciais e temporais" (CALDAS, 2009 citado por SANTOS, 2015, p. 61).

Esperamos que em nossas próximas obras haja a possibilidade de estarmos juntos novamente - intérprete-criador e público -, no mesmo tempo e espaço, ao passo que os encontros presenciais sejam retomados e que estejamos seguros para trocar afectos. Talvez a experiência de fruição mediada pelas telas dos computadores, celulares e tablets façam emergir outras relações entre a obra e o espectador, já que as alterações de tempo e espaço podem reverberar nos modos como nosso corpo produz sentidos.

No entanto, enquanto não vivenciamos esse tempo, esperamos que o Hiatos do Humano possa produzir afectos em seus espectadores. Como nos lembra Ferreira (2018, p. 77) "[...] o que dura são os afectos. A memória como um estado de corpo afectado, de espectador em estado de afecção com a obra vista e percebida". Quem afecta, também é afectado. Assim, "trata-se não somente de produção de imagem, mas de composição de afectos. Da imagem como afecção do corpo" 


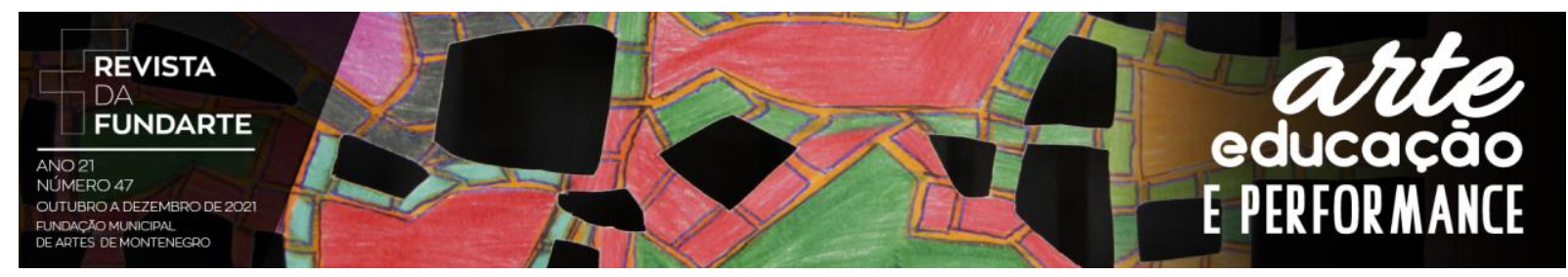

(FERREIRA, 2018, p. 77). Talvez, a busca por produzir afectos e sentidos por meio das telas e da arte seja o que nos mantém e nos situa como humanos.

Desejamos, também, que esses afectos produzam em nossos corpos a ação de esperançar. Quando nos encontramos diante de um buraco entre as rochas temos duas opções, atravessá-lo de forma a descobrir o que tem na outra rocha e quais paisagens essa travessia poderá nos proporcionar, ou, simplesmente, buscar outro percurso. Porém, desistir de seguir nosso caminho não pode ser uma opção. Ao encontrar um buraco no caminho, uma fenda no espaço, uma lacuna em nossos pensamentos, um hiato em nossas vidas, precisamos lembrar do verbo esperançar, assim saltaremos as lacunas, os buracos em nossos caminhos de uma forma mais suave, decidida e repleta de afectos, mesmo sem saber ao certo como ou onde vamos cair, escolheremos saltar. Esperançar!

\section{Referências:}

BACHELARD, Gaston. Dialética da duração. Ática, 1994.

BICUDO, Maria Aparecida Viggiani. Sobre a fenomenologia. In: BICUDO, M.A.V.; ESPOSITO, V.H.C. (ORGS). Pesquisa qualitativa em educação: um enfoque fenomenológico. Piracicaba: Unimep, p. 15-22, 1994.

CAMARGO, Emerson. A Dança de Relações e Experimentação. Curitiba: Íthala, 2013.

CARVALHO FILHO, José Ernane Carneiro. O tempo em Bachelard: uma ruptura com o continuísmo bergsoniano. IDEAÇÃO, Feira de Santana, n. 25, v. 2, 2012.

CERBINO, Beatriz; MENDONÇA, Leandro. Audiovisual, videodança e dança: conceitos e devoramentos. Anais da ANPAP, 2011.

COHEN, Renato. Performance como linguagem: criação de um tempo-espaço de experimentação. São Paulo: 3.ed. Editora Perspectiva, 2013.

DE MEDEIROS, Euclides Antunes; CORMINEIRO, Olivia Macedo Miranda. Caminhos entre imaginação e método historiográfico na obra cem anos de solidão. Revista Brasileira do Caribe, São Luís, MA, Brasil, v. 19, n. 36, 2018.

FERNANDES, Ciane. A prática como pesquisa e a abordagem somáticoperformativa. Anais ABRACE, v. 15, n. 1, 2014. 


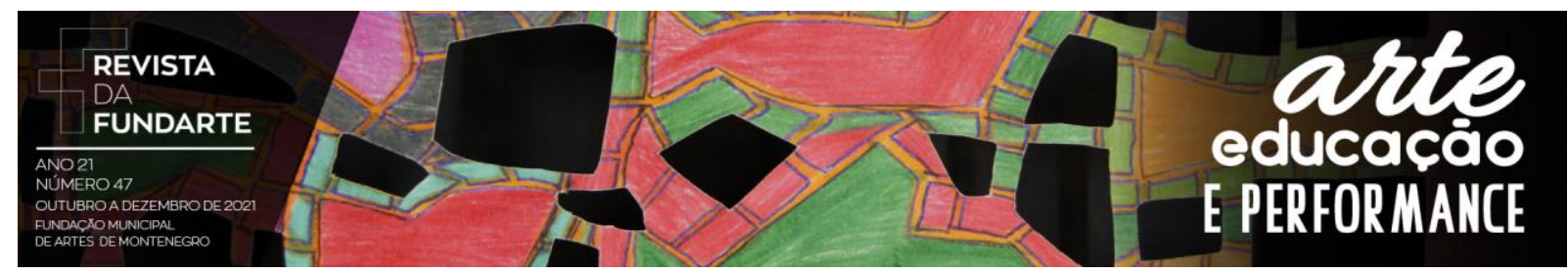

FERREIRA, Larissa. Dança transmídia: compondo as fissuras do (in)visível. Revista VIS (UNB), v. 17, p. 67-78, 2018.

FREIRE, Paulo. Pedagogia da autonomia: saberes necessários à prática educativa. 52ª ed. Rio de Janeiro: Paz \& Terra, 2015.

FREIRE, Paulo. Pedagogia da Esperança. São Paulo: Paz e Terra, 2014.

GARCIA, Ângela; HAAS, Aline Nogueira. Ritmo e dança. 2. ed. - Canoas: Editora da ULBRA, 2006.

GLUSBERG, Jorge. A arte da performance. Tradução Renato Cohen. São Paulo: 3.ed. Editora Perspectiva, 2013.

GUSTSACK, Felipe. Hip-Hop: educabilidades e traços culturais em movimento. 2003. 222 f. Tese (Doutorado em Educação) - Universidade Federal do Rio Grande do Sul. Faculdade de Educação, Porto Alegre, 2003.

HASEMAN, B. Manifesto pela pesquisa performativa. In: CERASOLI JÚNIOR, U. e colaboradores (org.). Resumos do Seminário de Pesquisas em Andamento PPGAC/USP - São Paulo: PPGAC-ECA/USP, v.3, n.1, 2015.

HOLANDA, Neto; LIMA, Valesca. Cultural movements and political actions in during the Covid-19 pandemic (Movimentos e ações político-culturais do Brasil em tempos de pandemia da Covid-19). Interface: a Journal for and about Social Movements, Sharing stories of struggles: Mayday, 2020. Disponível em: http://mural.maynoothuniversity.ie/12876/1/Holanda-e-Lima.pdf Acessado em 18/07/2020.

MARQUES, Isabel A. Ensino de dança hoje: textos e contextos. 6 ed. São Paulo: Cortez, 2011.

MINISTÉRIO DA SAÚDE. Sobre a doença: o que é COVID-19. Disponível em: https://coronavirus.saude.gov.br/sobre-a-doenca . Acessado em: 23/10/2020.

MORAIS, Sergio Bruck de. Refletindo sobre processos criativos a partir da tradução de A linguagem da dança, de Mary Wigman. Tese (Doutorado em Artes da Cena) Universidade Estadual de Campinas. Instituto de Artes, Campinas, 2019.

MORENO, Rosangela Carrilo; ALMEIDA, Ana Maria F. O engajamento político dos jovens no movimento hip-hop. Revista Brasileira de Educação, v. 14, n. 40, p. 130 142, 2009.

PASSOS, Juliana Cunha. Rolf Gelewski e a improvisação na criação em dança: formas, espaço e tempo. Curitiba: Editora Prismas, 2015.

PEIRANO, Mariza. Rituais ontem e hoje. Rio de Janeiro: Jorge Zahar, 2003. 


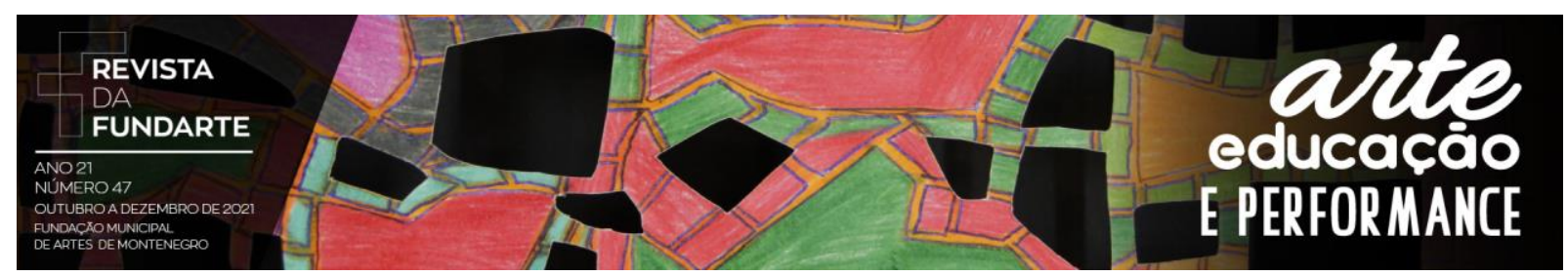

RICHTER, Sandra. Bachelard e a experiência poética como dimensão educativa da arte. Educação (UFSM), v. 31, n. 2, 2006.

SALLES, Cecilia. Redes da criação - a construção da obra de arte. Horizonte, 2016.

SANTOS, Bruna Bardini dos. Videodança na escola: reflexões sobre o corpo e a dança no contexto escolar. Dissertação (mestrado) - Universidade Federal do Paraná, Setor de Educação, Programa de Pós-Graduação em Educação. 2015.

SANTOS, Maíra Simões Claudino. Composição Instantânea: formação coreográfica do artista da dança e de seu corpo-realidade. Revista Brasileira de Estudos da Presença, v. 8, n. 1, p. 167-193, 2018.

VIANNA, Klauss. A dança. Summus Editorial, 2005. 